OPEN ACCESS

Edited by:

ZhongQiang Li,

Hubei University, China

Reviewed by:

Lina Fusaro,

Sapienza University of Rome, Italy

Enhua Li,

Institute of Geodesy and Geophysics

(CAS), China

*Correspondence:

Hong Sheng Jiang

jhs@wbgcas.cn

Specialty section:

This article was submitted to

Functional Plant Ecology,

a section of the journal

Frontiers in Plant Science

Received: 26 June 2018 Accepted: 12 December 2018

Published: 07 January 2019

Citation:

Cao Y, Liu Y, Ndirangu L, Li W,

Xian L and Jiang HS (2019) The

Analysis of Leaf Traits of Eight Ottelia

Populations and Their Potential Ecosystem Functions in Karst

Freshwaters in China.

Front. Plant Sci. 9:1938.

doi: 10.3389/fp/s.2018.01938

\section{The Analysis of Leaf Traits of Eight Ottelia Populations and Their Potential Ecosystem Functions in Karst Freshwaters in China}

\author{
Yu Cao ${ }^{1,2}$, Yang Liu ${ }^{1,2,3}$, Leah Ndirangu ${ }^{1,2,3,4}$, Wei Li ${ }^{1,2}$, Ling Xian ${ }^{1,2,3}$ and \\ Hong Sheng Jiang ${ }^{1,2 *}$
}

${ }^{1}$ Key Laboratory of Aquatic Botany and Watershed Ecology, Wuhan Botanical Garden, Chinese Academy of Sciences, Wuhan, China, ${ }^{2}$ Hubei Key Laboratory of Wetland Evolution and Ecological Restoration, Wuhan Botanical Garden, Chinese Academy of Sciences, Wuhan, China, ${ }^{3}$ University of Chinese Academy of Sciences, Beijing, China, ${ }^{4}$ Sino-African Joint Research Center, Chinese Academy of Sciences, Wuhan, China

Submerged macrophytes play a structuring role in the shallow freshwater ecosystem by increasing the heterogeneous state in freshwaters. The macrophytes in genus Ottelia were featured for their broad leaves, which might consequently produce specialized functions that differed from other submerged species. To explore the potential ecological role of Ottelia, a field investigation was conducted on leaf traits in eight populations of Ottelia ranging from the southwestern Yunnan-Guizhou plateau to the southern Hainan island in China covering a distance of $>1,700 \mathrm{~km}$. The eight populations included all the extant Ottelia species and varieties in China except the well-documented O. alismoides. Carbon-related traits [bicarbonate usage, photosynthetic characteristics, capability of Crassulacean acid metabolism (CAM)], pigment content and parameters of chlorophyll fluorescence, morphology and mass of the leaves were determined. The different populations showed distinct functional traits of mature leaves; 0 . acuminata var. songmingensis had the thickest and longest leaf with $\mathrm{CaCO}_{3}$ precipitation on the both sides of the leaf, and $O$. cordata showed putative CAM activity with the highest diel acidity changes $12.5 \mu$ equiv $\mathrm{g}^{-1} \mathrm{FW}$. Our results indicated an important role of Ottelia populations in carbon cycling as the dominant species in karst freshwaters in China.

Keywords: Ottelia, Crassulacean acid metabolism, bicarbonate usage, leaf traits, shallow freshwaters

\section{INTRODUCTION}

Submerged macrophytes are considered as one of the most important primary producers in shallow oligotrophic freshwaters and strongly affect the nutrient turnover for freshwater ecosystem (Wetzel, 1964; Epstein et al., 2012; Olsen et al., 2017). In addition, submerged macrophytes can interact with other organisms, e.g., protecting the zooplankton from fish grazing or providing substrate for periphyton growth (Jeppesen et al., 1998; Cao et al., 2014, 2017). Plant functional traits, as a series of core properties describing the growth, survival and reproduction of plants, are useful tools to explore the ecological function of submerged macrophytes in freshwater systems (Grime, 1974). Most studies related with plant functional traits are focusing on terrestrial forest or grass (Kraft et al., 2008; Klimešová et al., 2016). For example, Kraft et al. (2015) stated that 
using the combination of functional traits (e.g., the growth form), but not simplistic usage of single functional trait, was important to infer community assembly processes in grassland. For submerged macrophytes, there are only few recent studies related with functional traits, which have investigated the functional traits at the community level along water depth gradients in natural lakes (Fu et al., 2014, 2018; Liu and Wang, 2018).

Leaf is the most important photosynthetic organ, and leaf traits are one of central plant functional traits (Petter et al., 2016; Damián et al., 2018). Especially the concept of 'leaf economic spectrum' (LES) has revealed the importance of leaf traits; a typical trade-off between leaf functional traits of $>2,000$ species has been found, which shows that leaves with the higher photosynthesis rate are featured with shorter life span and lower leaf mass per area (MPA; Wright et al., 2004). In addition, Cornwell et al. (2010) linked the decomposition rate of terrestrial plant litter with the position of the species in the LES, indicating a close relationship between leaf traits and ecosystem function. The submerged macrophytes also have contrasting decomposition rates (Potamogeton crispus vs. P. macckianus), which can significantly affect the carbon cycling in shallow lakes (Wang et al., 2016). However, none of submerged species has been included in LES. Compared with other submerged species, leaves of Ottelia are usually much broader with long petiole, and meantime these leaves can play an extra role in ecosystem carbon cycling through $\mathrm{CaCO}_{3}$ precipitation on the leaf surface compared with those of terrestrial plants (Prins et al., 1982; Yin et al., 2017).

The genus Ottelia widely distributes from tropical to temperate areas and consists of ca. 21 species in the globe ${ }^{1}$. Among these species, $O$. alismoides has been under extensive investigation. The species used to widely spread in China and presently under threat due to habitat fragmentation (Chen et al., 2008). As an annual species, the seed germination was featured with density dependence (Yin et al., 2009, 2013). In addition, $O$. alismoides was found with three carbon concentrating mechanisms, i.e., bicarbonate usage, Crassulacean acid metabolism (CAM) and C4 (Zhang et al., 2014; Shao et al., 2017), which showed potentially strong influence on carbon cycling in freshwater ecosystems dominated by the species (Maberly and Gontero, 2017; Shao et al., 2017). While other species in genus Ottelia were less investigated, and the main focus was about the phylogenetic relationship among these species based on the characteristic of isozyme, flower, seed and qualitative description of the species (Kaul, 1969; Cook et al., 1984; He, 1991). For instance, Chen et al. (2017) has studied five recorded varieties of O. acuminata, an endemic species in China, based on molecular proofs, and the authors stated that most of collected varieties reflected genetically differentiated group, and the genetic divergences could be linked with the past tectonic movements. Other than O. alismoides, the Ottelia species or varieties grew in a localized and relatively stable karst freshwater (Chen et al., 2017). Consistently, Li et al. (2018) assumed a fast speciation process of O. acuminata due to geographic features in these areas.

${ }^{1}$ http://foc.eflora.cn/content.aspx?TaxonId=123432, accessed on 06-28-2018.
As the dominant submerged species in pristine karst freshwaters, populations of $O$. acuminata are potentially important factors of carbon source/sink in the ecosystem (Wang et al., 2017). Therefore, an in-situ investigation of leaf traits could give the indispensable information of ecological functions of the Ottelia populations in the freshwater ecosystem.

In this study, we sampled eight Ottelia populations across the distance of $1,700 \mathrm{~km}$ in karst freshwaters in China, and we hypothesized that leaf traits of the Ottelia populations can correlate with phylogenetic relationship, and a detailed analysis of leaf traits facilitates to reveal the role of Ottelia populations in the carbon cycling in karst freshwaters.

\section{MATERIALS AND METHODS}

Eight populations in Luguhu (LG), Heqing (HQ), Jianchuan (JC), Eryuan (EY), Guiyang (GY), Songming (SM), Jingxi (JX), and Haikou (HN) were distributed in the provinces of Yunnan, Guizhou, Guangxi and Hainan, covering a distance of $>1,700 \mathrm{~km}$. Most of the collected species grew in localized karst freshwaters, and the geographic information of the sampling sites was listed in Table 1.

The physico-chemical variables in each site including atmospheric pressure (AP), dissolved oxygen (DO), conductivity (C), total dissolved solid (TDS), $\mathrm{pH}$, and oxidation-reduction potential (ORP) were measured in situ by a YSI Pro Plus multiparameter meter (Xylem, United States). Photosynthetically active radiation (PAR) was determined at the water depth of $0 \mathrm{~cm}$ and $40 \mathrm{~cm}$ by a LI-1400 Data Logger and a LI-192 underwater quantum sensor (LI-COR, United States), and the light attenuation was calculated assuming an exponential decay of PAR in the water column (Kirk, 1977). Two or more liters of water samples were collected by a plastic tube sampler and separated into aliquot for the determination of total nitrogen (TN), total phosphorus (TP), alkalinity (Alk), and phytoplankton chlorophyll a (PhyChla). Samples for TN and TP were frozen at $-20^{\circ} \mathrm{C}$, transferred into lab and determined by the $\mathrm{K}_{2} \mathrm{~S}_{2} \mathrm{O}_{8}$ digestion (Huang et al., 1999). Alkalinity (Alk) was determined using the Gran titration of $0.1 \mathrm{M} \mathrm{HCl}$. At least 11 of water was filtered through the GF/C filter for the determination of PhyChla, and the filter was extracted by $95 \%$ ethanol and determined by a spectrophotometer (Jespersen and Christoffersen, 1987).

Based on Kraft et al. (2015), we used the combination of functional traits (not a single trait) to evaluate the ecological functions of the leaves of Ottelia. We classified the leaf traits into three categories: leaf morphology and mass, pigment content and parameters of chlorophyll fluorescence and carbon-related traits (bicarbonate usage, capability of CAM and photosynthetic characteristics).

The individuals of Ottelia were harvested gently from the ponds or rivers. Twenty intact leaves were randomly chosen for the determination of leaf morphology and fresh weight. The maximum width and the maximum length were measured by a ruler, and the thickness was determined by a vernier caliper. The leaf was then placed into a standard plate and photographed for the determination of the leaf area (Shao et al., 2017). Afterward, 
TABLE 1 | The geographic information of the sampling sites.

\begin{tabular}{|c|c|c|c|c|c|}
\hline Taxon & Population code & Location & Latitude (N) & Longitude (E) & Habitat \\
\hline O. acuminata var. crispa & LG & Luguhu, Yunnan & $27.67^{\circ}$ & $100.76^{\circ}$ & Lake \\
\hline \multirow[t]{3}{*}{ O. acuminata var. acuminata } & $\mathrm{HQ}$ & Heqing, Yunnan & $26.55^{\circ}$ & $100.17^{\circ}$ & Pond \\
\hline & $J C$ & Jianchuan, Yunnan & $26.53^{\circ}$ & $99.96^{\circ}$ & Pond and stream \\
\hline & EY & Eryuan, Yunnan & $26.16^{\circ}$ & $99.93^{\circ}$ & Lake \\
\hline O. balansae & GY & Guiyang, Guizhou & $26.43^{\circ}$ & $106.67^{\circ}$ & Pond \\
\hline O. acuminata var. songmingensis & $\mathrm{SM}$ & Songming, Yunnan & $25.27^{\circ}$ & $102.88^{\circ}$ & Pond and stream \\
\hline O. acuminata var. jingxiensis & $J X$ & Jingxi, Guangxi & $24.84^{\circ}$ & $103.45^{\circ}$ & River \\
\hline O. cordata & $\mathrm{HN}$ & Haikou, Hainan & $19.94^{\circ}$ & $110.40^{\circ}$ & Stream \\
\hline
\end{tabular}

TABLE 2 | The physic-chemical variables of the sampling sites.

\begin{tabular}{|c|c|c|c|c|c|c|c|c|c|c|c|c|}
\hline $\begin{array}{l}\text { Sampling } \\
\text { sites }\end{array}$ & $\begin{array}{c}\text { Temp } \\
\left({ }^{\circ} \mathrm{C}\right)\end{array}$ & $\begin{array}{c}\mathrm{AP} \\
\mathrm{mmHg}\end{array}$ & $\begin{array}{c}\text { DO } \\
\mathrm{mg} \mathrm{L}^{-1}\end{array}$ & $\begin{array}{c}\text { C } \\
\text { us } \mathrm{cm}^{-1}\end{array}$ & $\begin{array}{c}\text { TDS } \\
\mathrm{mg} \mathrm{L}^{-1}\end{array}$ & $\mathrm{pH}$ & $\begin{array}{l}\text { ORP } \\
\mathrm{mV}\end{array}$ & $\begin{array}{l}\mathrm{Kd} \\
\mathrm{m}^{-1}\end{array}$ & $\begin{array}{c}\text { Alk } \\
\mathrm{mmol} \mathrm{L}^{-1}\end{array}$ & $\begin{array}{l}\text { PhyChla } \\
\mathrm{mg} \mathrm{L}^{-1}\end{array}$ & $\begin{array}{c}\mathrm{TN} \\
\mathrm{mg} \mathrm{L}^{-1}\end{array}$ & $\begin{array}{c}\text { TP } \\
\mu \mathrm{g} \mathrm{L}^{-1}\end{array}$ \\
\hline LG & 21.1 & 550.9 & 6.63 & 219.2 & 153.4 & 8.94 & -0.3 & 0.13 & 1.81 & 1.0 & 0.28 & 37 \\
\hline $\mathrm{HQ}$ & 17.1 & 585.1 & 8.59 & 216.4 & 165.1 & 8.84 & 17.4 & 0.16 & 2.36 & 0.9 & 0.67 & 26 \\
\hline $\mathrm{JC}$ & 16.3 & 584.8 & 14.7 & 288.5 & 213.6 & 7.98 & 167.2 & 0.58 & 3.15 & 2.5 & 0.69 & 29 \\
\hline EY & 23.4 & 566.5 & 6.33 & 213.0 & 143.2 & 8.87 & -27 & 0.72 & 1.43 & 5.0 & 1.21 & 59 \\
\hline GY & 23.1 & 666.9 & 7.65 & 469.6 & 317.2 & 7.74 & 183.9 & 0.47 & 3.10 & 1.5 & 2.47 & 11 \\
\hline SM & 20.3 & 607.9 & 7.25 & 281.5 & 204.1 & 8.39 & 114.6 & $-{ }^{a}$ & 2.80 & 0.8 & 1.77 & 22 \\
\hline$J X$ & 22.2 & 685.8 & 6.52 & 430.6 & 297.3 & 7.79 & 51.2 & 0.31 & 3.95 & 0.5 & 2.31 & 29 \\
\hline $\mathrm{HN}$ & 30.8 & 755.5 & 2.83 & 273.7 & 165.8 & 7.33 & 137.3 & 0.88 & 1.52 & 0.3 & 2.62 & 69 \\
\hline
\end{tabular}

${ }^{a} K_{d}$ is not determined in the site SM.

the leaf was blotted by an absorbent paper and submerged into a half-filled measuring cylinder, and the volume changes of the water in the cylinder was estimated as the leaf volume.

Leaf pigment content including chlorophyll a (Chla), chlorophyll b (Chlb), and carotenoids (Car) was measured by the extraction of 95\% ethanol (Huang et al., 1999). The parameters of leaf chlorophyll fluorescence were determined by chlorophyll fluorometer MONITORING-PAM (Walz, Germany) following the methods in Kramer et al. (2004) and Jiang et al. (2017). Ф is derived from a pure 'lake' or 'puddle' model referring to the fraction of the energy absorbed by photosystem (PS) II that is used in photochemistry. $\Phi_{\mathrm{NPQ}}$ and $\Phi_{\mathrm{NO}}$ are used to estimate the flux of excitation energy into the non-photochemical pathways, and $\Phi_{\mathrm{NPQ}}$ refers to the yield induced by downregulatory processes, $\Phi_{\mathrm{NO}}$ for the yield of other energy losses. $\Phi_{\mathrm{PSII}}, \Phi_{\mathrm{NPQ}}$, and $\Phi_{\mathrm{NO}}$ were obtained by an induction curve by setting the PAR of the active light at $127 \mu \mathrm{mol} \mathrm{E}-1 \mathrm{~s}^{-2}$. $\mathrm{rETR}_{\max }$ and $I_{\mathrm{k}}$ were acquired by a rapid light curve using the 12 steps of PAR gradients from ca. 2 to $1500 \mu \mathrm{mol} \mathrm{E}^{-1} \mathrm{~s}^{-2}$.

The end-point $\mathrm{pH}$ in $1 \mathrm{mM} \mathrm{Na} / \mathrm{KHCO}_{3}$ solution for the leaves of each population was determined by a $\mathrm{pH}$-drift method (Zhang et al., 2014). CAM capability was determined according to the diel change of acidity in leaves using the titration of $0.01 \mathrm{M} \mathrm{NaOH}$ to pH 8.3 (Shao et al., 2017). Photosynthesis rates were determined by measuring the changes of DO in the $50 \mathrm{ml}$ glass bottles prior to and $30 \mathrm{~min}$ after adding the leaves into the bottle at the concentrations of $0,1,2,4,6,8$, and $10 \mathrm{mM}$ dissolved inorganic carbon (DIC, represented as $\mathrm{Na} / \mathrm{KHCO}_{3}$ ), respectively. As a commonly used method, the DIC in the water was stable during the determination (Zhang et al., 2014; Clement et al., 2016).
The light was provided by LED light bulb (ca. $100 \mu \mathrm{mol} \mathrm{E}^{-1} \mathrm{~s}^{-2}$ ), and the dark respiration rates were determined in the brown bottles prior to and $30 \mathrm{~min}$ after adding the leaves into the bottle at the concentrations of 0 and $10 \mathrm{mM}$ DIC. The net photosynthesis rates at different concentrations of DIC was fitted to a slightly modified Michaelis-Menten equation that considered the compensation point for DIC (Clement et al., 2016). The equation is:

$$
\text { Net photosynthesis rate }=\frac{V_{\max } *(\mathrm{DIC}-\mathrm{CP})}{K_{\text {half }}+(\mathrm{DIC}-\mathrm{CP})}
$$

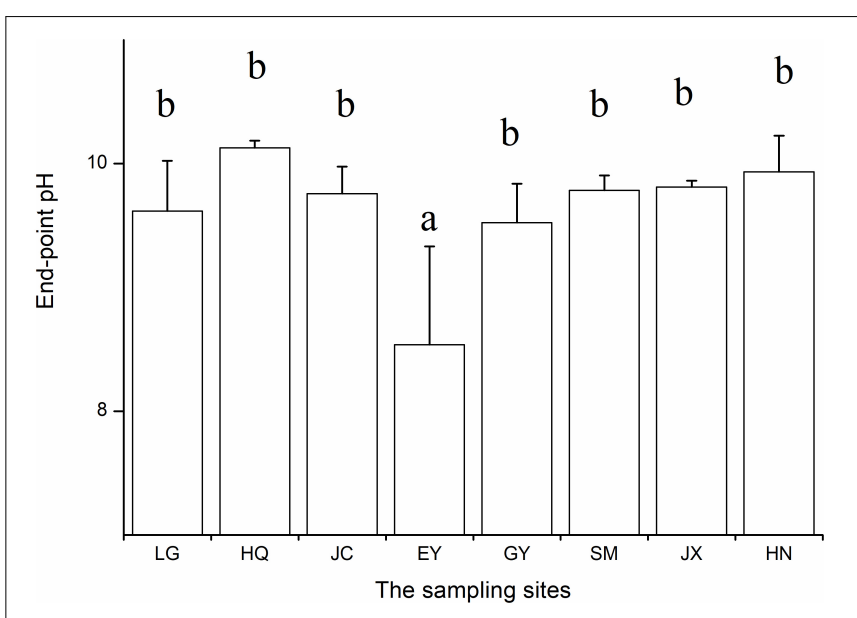

FIGURE 1 | The end-point $\mathrm{pH}$ of the $\mathrm{pH}$-drift experiments in the eight populations. 

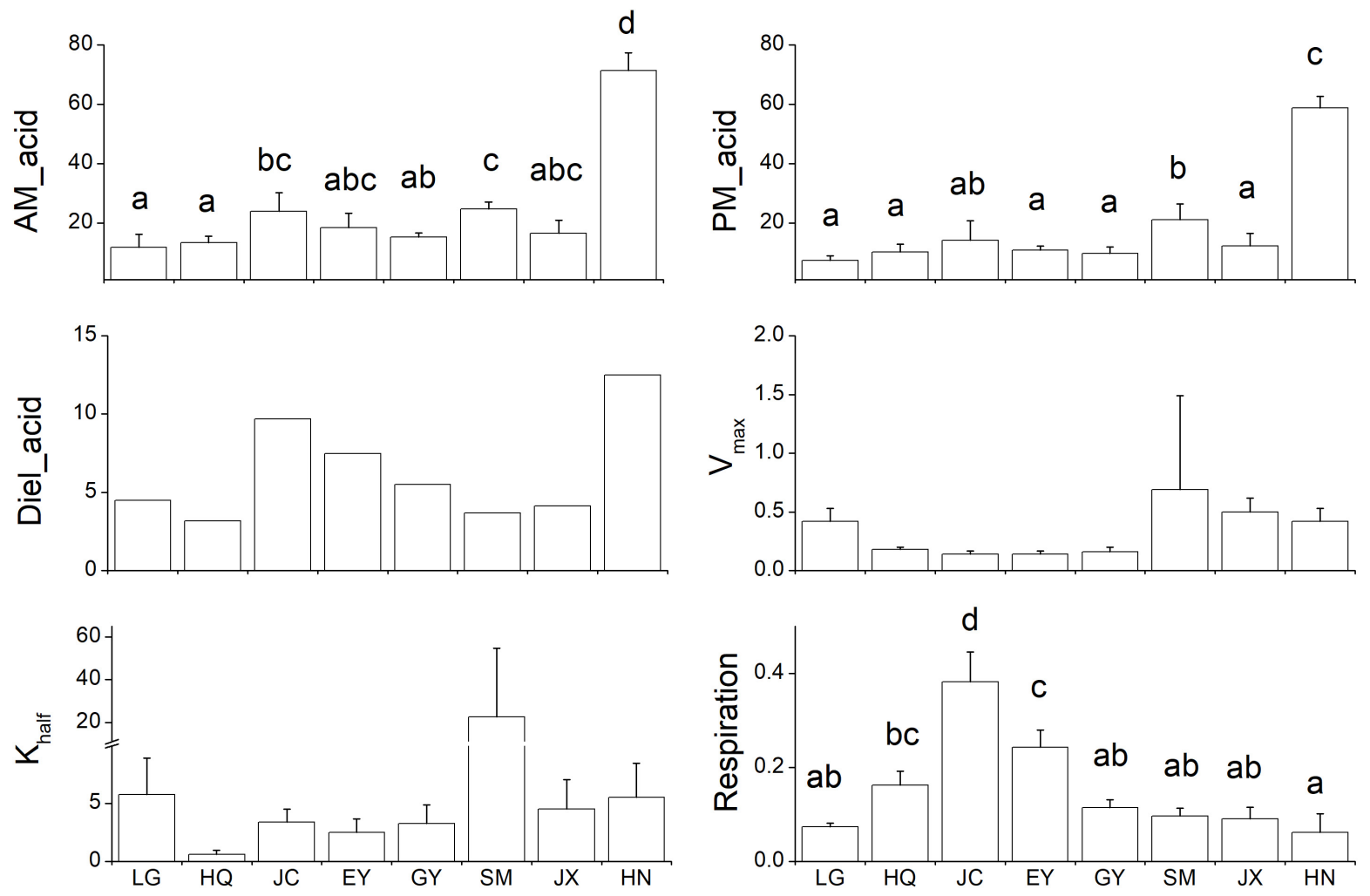

The sampling sites

FIGURE 2 | The six carbon-related leaf traits in the eight Ottelia populations. AM_acid and PM_acid is the acidity of the leaves at ca. 7 am and 7 pm (unit: $\mu$ equiv $\mathrm{g}^{-1}$ FW). Diel_acid is the changes between mean AM_acid and mean PM_acid (unit: $\mu$ equiv $\mathrm{g}^{-1}$ FW). $V_{\max }$ is the maximum rate of net photosynthesis (unit: $\mathrm{mg}$ $\mathrm{O}_{2} \mathrm{~g}^{-1} \mathrm{FW} \mathrm{h}^{-1}$ ), and $K_{\text {half }}$ is the concentration of dissolved inorganic carbon producing half-maximal rates of net photosynthesis calculated from the Michaelis-Menten equation (unit: $\mathrm{mM}$ ). Respiration is the respiration rate in the dark (unit: $\mathrm{mg} \mathrm{O}_{2} \mathrm{~g}^{-1} \mathrm{FW} \mathrm{h}^{-1}$ ). Due to the method of calculation, Diel_acid, $V_{\text {max }}$ and $K_{\text {half }}$ are not analyzed by ANOVA and therefore no statistical results for post hoc test. The different letters in the figure indicate the significant difference among the eight population.

where (rate as $\mathrm{mg} \mathrm{O}_{2} \mathrm{~g}^{-1} \mathrm{FW} \mathrm{h}^{-1}$ and concentration as $\mathrm{mM}$ ) $V_{\max }$ is the maximum rate of net photosynthesis; CP is the DIC compensation concentration; $K_{\text {half }}$ is the concentration of DIC producing half-maximal rates of net photosynthesis.

TABLE 3 | The Pearson correlation between six carbon-related leaf traits in the eight populations.

\begin{tabular}{lccccr}
\hline & AM_acid & PM_acid & $\boldsymbol{V}_{\max }$ & Respiration & $\boldsymbol{K}_{\text {half }}$ \\
\hline Diel_acid & 0.804 & 0.729 & -0.027 & 0.240 & 0.182 \\
AM_acid & & $0.993^{*}$ & 0.307 & -0.251 & 0.393 \\
PM_acid & & & 0.358 & -0.336 & 0.416 \\
$V_{\max }$ & & & & -0.718 & 0.693 \\
Respiration & & & & & -0.525
\end{tabular}

AM_acid and PM_acid is the acidity of the leaves at ca. 7 am and 7 pm (unit: $\mu$ equiv $g^{-1}$ FW). Diel_acid is the changes between mean AM_acid and mean PM_acid (unit: $\mu$ equiv $g^{-1} \mathrm{FW}$ ). $V_{\max }$ is the maximum rate of net photosynthesis (unit: $\mathrm{mg} \mathrm{O}_{2} \mathrm{~g}^{-1} \mathrm{FW} \mathrm{h}^{-1}$ ). Respiration is the respiration rate in the dark (unit: $\mathrm{mg}$ $\left.\mathrm{O}_{2} g^{-1} \mathrm{FWh} h^{-1}\right)$. K half is the concentration of dissolved inorganic carbon producing half-maximal rates of net photosynthesis calculated from the Michaelis-Menten equation (unit: $m M$ ). The star $\left(^{*}\right.$ ) indicates a correlation coefficient $>0.9$.
Five replicates were measured for the CAM capability, and three replicates were measured for other indicators of macrophyte leaves.

\section{Statistical Analysis}

For most indicators of leaf traits, one-way ANOVA was used to analyze the difference among the eight populations. Post hoc test was conducted using Tukey method at the significance level of 0.05 . The data was log-transformed to achieve variance homogeneity prior to the statistical analyses, if needed. Because the diel change of leaf acidity was determined by the difference of mean leaf acidity at dusk and at dawn and thus had no replicates, it was not quantitatively analyzed by ANOVA. $V_{\max }$ and $K_{\text {half }}$ were estimated by fitting the Michaelis-Menten equation with standard errors (as stated above). The traits were classified into three categories: leaf morphology and mass, pigment content and parameters of chlorophyll fluorescence and carbon-related traits (bicarbonate usage, capability of CAM and photosynthetic characteristics). Pearson correlation and the cluster analysis were analyzed within each aspect. In this study the correlation coefficient that is $>0.9$ was defined as a strong relationship 


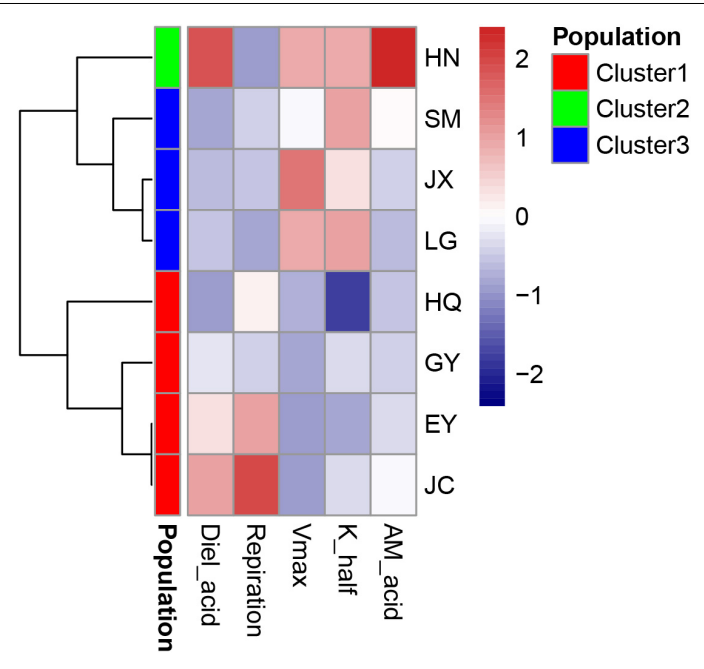

FIGURE 3 | The cluster analysis of carbon-related leaf traits in the eight Ottelia populations. AM_acid is the acidity of the leaves at ca. 7 am (unit: $\mu$ equiv $\mathrm{g}^{-1}$ FW). Diel_acid is the changes of leaf acidity between ca. 7 am (dusk) and 7 pm (dawn) (unit: $\mu$ equiv $\mathrm{g}^{-1} \mathrm{FW}$ ). $V_{\max }$ is the maximum rate of net photosynthesis (unit: $\mathrm{mg} \mathrm{O}_{2} \mathrm{~g}^{-1} \mathrm{FW} \mathrm{h}^{-1}$ ), and $K_{\text {half }}$ is the concentration of dissolved inorganic carbon producing half-maximal rates of net photosynthesis calculated from the Michaelis-Menten equation (unit: $\mathrm{mM}$ ). Respiration is the respiration rate in the dark (unit: $\mathrm{mg} \mathrm{O}_{2} \mathrm{~g}^{-1} \mathrm{FW} \mathrm{h}^{-1}$ ). between the leaf traits, and only one trait was included in the further clustering analysis to reduce the statistical bias. The clustering analysis was conducted by package 'mclust' using the 'euclidean distance' after 'scale' the data. All the statistical analyses were determined in R 3.4.0. Data is presented in mean $\pm \mathrm{SD}$ if not explicitly stated.

\section{RESULTS}

\section{Physic-Chemical Conditions in the Eight Sampling Sites}

As shown in Table 2, most sites had low nutrient levels, low phytoplankton biomass, low light attenuation, and slight alkaline with relative high alkalinity, indicating a pristine status with clear water.

\section{pH-Drift}

At the end of the $\mathrm{pH}$-drift experiment $\mathrm{pH}$ was lowest in the EY population (Figure 1). After excluding the EY population, the end-point $\mathrm{pH}$ did not differ among the rest seven populations (ANOVA, $F=1.98, p>0.05)$. Only the end-point $\mathrm{pH}$ in the HQ population is $>10(10.13 \pm 0.06)$. Consistently, we observed that $\mathrm{CaCO}_{3}$ precipitation on the surface of the mature leaves
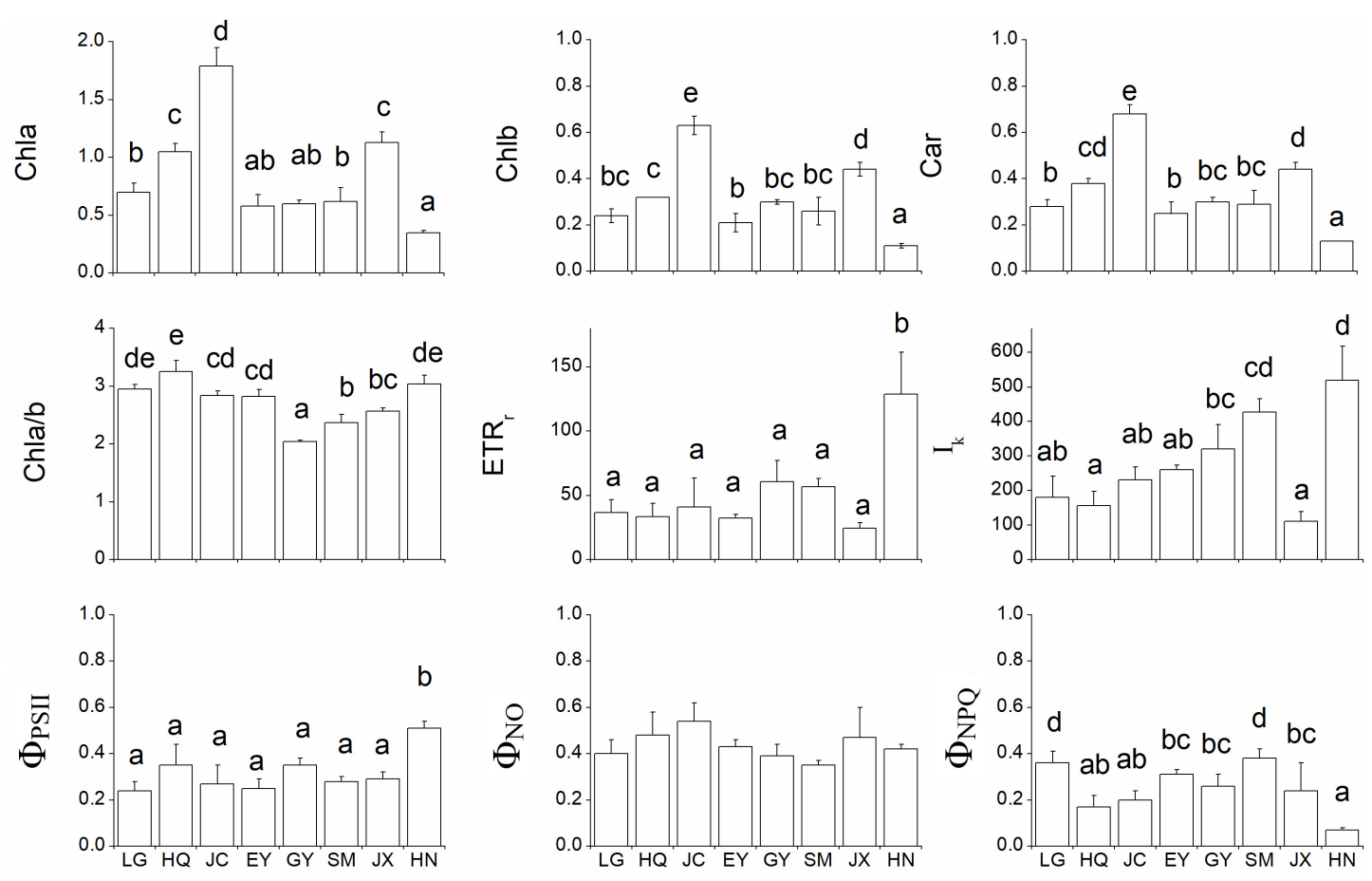

\section{The sampling sites}

FIGURE 4 | The nine pigment-related leaf traits in the eight populations. Chla, Chlb, Car, and Chla/b refer to the leaf chlorophyll a (unit: $\mathrm{mg} \mathrm{g}^{-1} \mathrm{FW}$ ), chlorophyll b (unit: $\mathrm{mg} \mathrm{g}^{-1} \mathrm{FW}$ ), carotenoids (unit: $\mathrm{mg} \mathrm{g}^{-1} \mathrm{FW}$ ) and the ratio of Chla and Chlb, respectively. rETR max (unit: $\mu$ mol electron $\mathrm{m}^{-2} \mathrm{~s}^{-1}$ ), $l_{\mathrm{k}}\left(\mu \mathrm{mol}\right.$ photon $\mathrm{m}^{-2} \mathrm{~s}^{-1}$ ), $\Phi_{\mathrm{PSII}}, \Phi_{\mathrm{NPQ}}$ and $\Phi_{\mathrm{NO}}$ are five leaf chlorophyll fluorescence parameters in the inductive curve and rapid light curve. The different letters in the figure indicate the significant difference among the eight population. 
TABLE 4 | The Pearson correlation between nine pigment-related leaf traits in the eight populations.

\begin{tabular}{|c|c|c|c|c|c|c|c|c|}
\hline & Chlb & Chla/b & Car & $\mathbf{r E T R}_{\max }$ & $I_{\mathrm{k}}$ & $\Phi_{\text {PSII }}$ & $\Phi_{\mathrm{NO}}$ & $\Phi_{\mathrm{NPQ}}$ \\
\hline Chla & 0.968* & 0.167 & $0.987^{*}$ & -0.524 & -0.583 & -0.415 & 0.833 & -0.117 \\
\hline Chlb & & -0.083 & $0.991^{*}$ & -0.528 & -0.542 & -0.448 & 0.732 & -0.031 \\
\hline Chla/b & & & 0.016 & 0.047 & -0.188 & 0.180 & 0.474 & -0.426 \\
\hline Car & & & & -0.556 & -0.563 & -0.475 & 0.761 & -0.024 \\
\hline rETR $\max$ & & & & & 0.880 & 0.872 & -0.311 & 0.576 \\
\hline$I_{k}$ & & & & & & 0.62 & -0.534 & -0.231 \\
\hline$\Phi_{\mathrm{PS} \|}$ & & & & & & & -0.075 & -0.822 \\
\hline$\Phi_{\mathrm{NO}}$ & & & & & & & & -0.507 \\
\hline
\end{tabular}

Chla, Chlb, Car, and Chla/b refer to the leaf chlorophyll a (unit: $\mathrm{mg} \mathrm{g}^{-1} \mathrm{FW}$ ), chlorophyll b (unit: $\mathrm{mg} \mathrm{g}^{-1} \mathrm{FW}$ ), carotenoids (unit: $\mathrm{mg} \mathrm{g}^{-1} \mathrm{FW}$ ) and the ratio of Chla and Chlb,

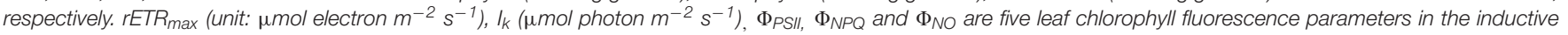
curve and rapid light curve. The star $\left(^{*}\right)$ indicates a correlation coefficient $>0.9$.

in all eight populations, especially on two sides of leaves of O. acuminata var. songmingensis.

\section{Carbon-Related Leaf Traits}

The leaf acidity at dawn and dusk was highest in the $\mathrm{HN}$ population (Figure 2 and Supplementary Table S1). The largest diel acidity change was also detected in the HN population, arriving at $12.5 \mu$ equiv $g^{-1} \mathrm{FW} . V_{\max }$ and $K_{\text {half }}$ were both high in the SM population but with large variation among the replicates. The respiration rate in the dark was highest in the JC population, intermediate in the EY population, and lowest in the $\mathrm{HN}$ population. Since there was strong correlation between the leaf acidity at dusk and at dawn (Table 3), the further cluster analysis only included the leaf acidity at dusk. The hierarchical clustering revealed three clusters in the eight populations (Figure 3 ). The HQ, GY, EY, and JC populations were grouped into one cluster, and the $\mathrm{HN}$ population were one cluster, with the rest three as one cluster.

\section{Leaf Pigment Content and Chlorophyll Fluorescence}

The leaf chlorophyll a (Chla), chlorophyll b (Chlb) and carotenoids were highest in the JC population, intermediate in the JX population and lowest in the HN population (Figure 4). In contrast, the ratio of Chla and Chlb (Chla/b) was lowest in the GY population.

Both $\mathrm{rETR}_{\max }$ and $\Phi_{\mathrm{PSI}}$ were significantly higher in the HN than in the other populations (Figure 4). $I_{\mathrm{k}}$ was low in the HQ and JX populations and high in the SM and HN populations. $\Phi_{\mathrm{NO}}$ did not differ among the eight populations while $\Phi_{\mathrm{NPQ}}$ was highest in LG and SM populations.

The strong correlation was found among Chla, Chlb, and carotenoids (Table 4). The cluster analysis discovers only one cluster for the eight populations (Figure 5).

\section{Leaf Traits of Morphology and Mass}

The SM population had the largest leaf length (reaching ca. $100 \mathrm{~cm}$ ), length/width ratio (Len/width), thickness, area, volume, fresh weight, MPA compared with the rest seven populations (Figure 6). While for leaf width, the EY population had the highest values, the LG population the lowest.
There was strong correlation among several traits of leaf morphology and mass (Table 5), and only four traits (leaf length, width, area and thickness) were included in the further hierarchical clustering analysis (Figure 7). Seven clusters were identified with the HQ and JC populations as one cluster, and other populations are distinct from each other.

\section{DISCUSSION}

Based on 24 leaf traits, we have provided a quantitative profile of the eight Ottelia populations in field. After grouped into three aspects (traits of morphology and mass, carbon-related traits and leaf pigment and chlorophyll florescence parameters), the

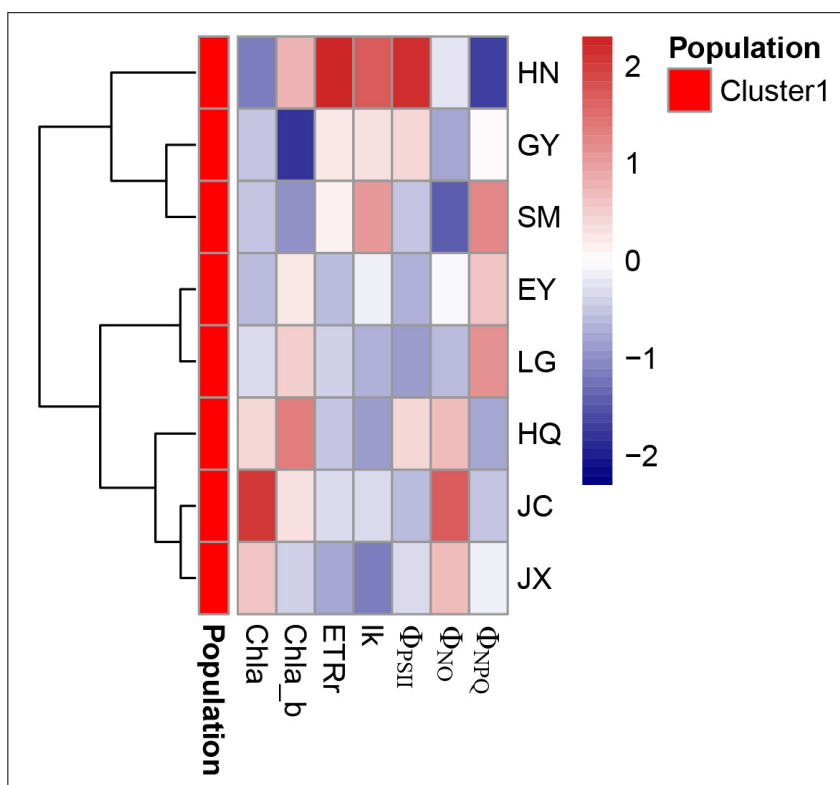

FIGURE 5 | The cluster analysis of pigment-related leaf traits in the eight populations. Chla, Chlb, Car, and Chla/b refer to the leaf chlorophyll a (unit: $\mathrm{mg} \mathrm{g}^{-1} \mathrm{FW}$ ), chlorophyll b (unit: $\mathrm{mg} \mathrm{g}^{-1} \mathrm{FW}$ ), carotenoids (unit: $\mathrm{mg} \mathrm{g}^{-1} \mathrm{FW}$ ) and the ratio of Chla and Chlb, respectively. rETR $R_{\max }$ (unit: $\mu$ mol electron $\mathrm{m}^{-2}$ $\mathrm{s}^{-1}$ ), $I_{\mathrm{k}}\left(\mu \mathrm{mol}\right.$ photon $\mathrm{m}^{-2} \mathrm{~s}^{-1}$ ), $\Phi_{\mathrm{PS} \|}, \Phi_{\mathrm{NPQ}}$, and $\Phi_{\mathrm{NO}}$ are five leaf chlorophyll fluorescence parameters in the inductive curve and rapid light curve. 


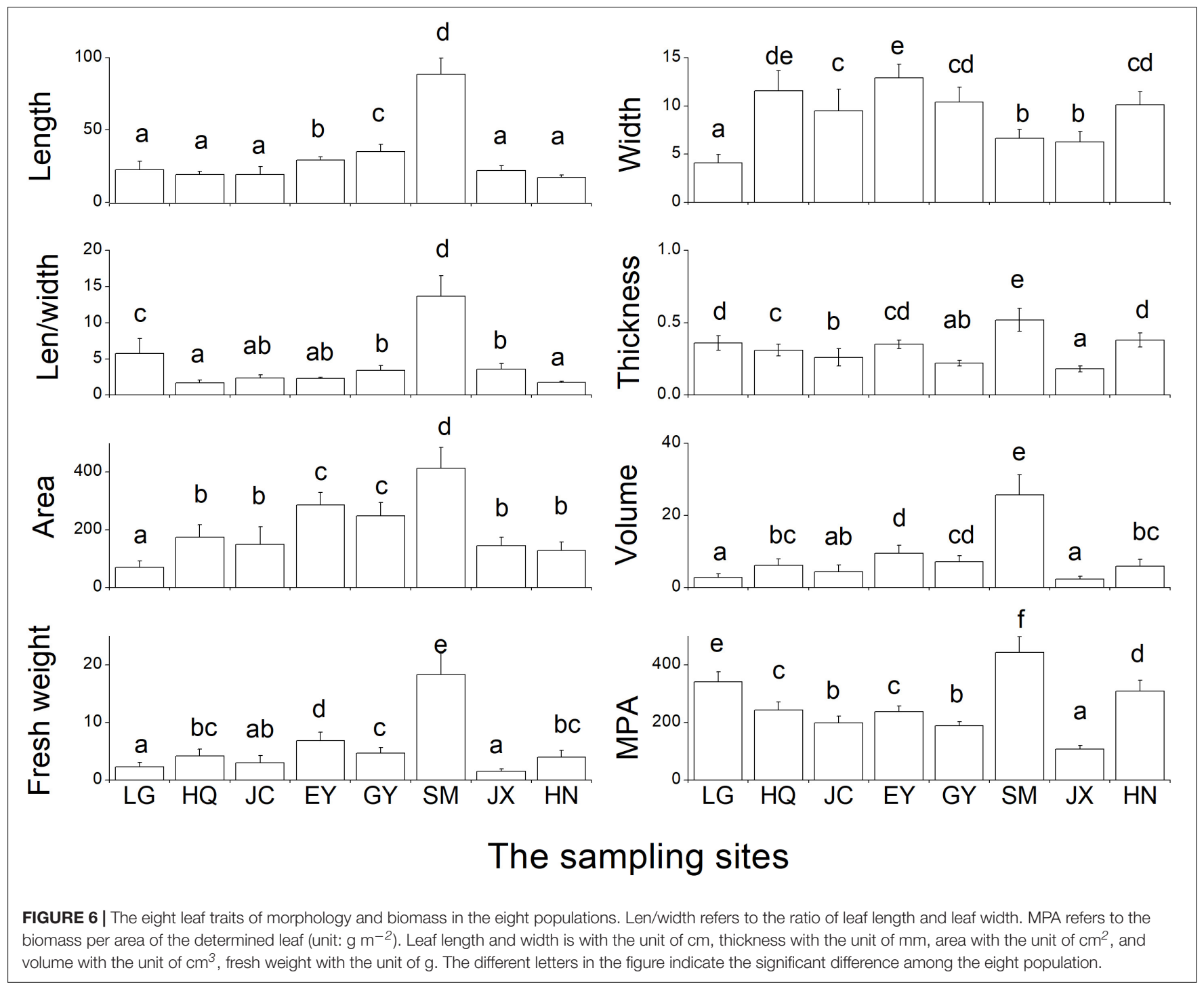

TABLE 5 | The Pearson correlation between eight leaf traits of morphology and biomass in the eight populations.

\begin{tabular}{|c|c|c|c|c|c|c|c|}
\hline & Width & Len/width & Area & Thickness & Volume & FW & MPA \\
\hline Length & -0.243 & $0.933^{*}$ & 0.870 & 0.680 & $0.960^{*}$ & $0.961^{*}$ & 0.649 \\
\hline Width & & -0.560 & 0.231 & -0.151 & -0.033 & -0.051 & -0.289 \\
\hline Len/width & & & 0.646 & 0.694 & 0.840 & 0.850 & 0.717 \\
\hline Area & & & & 0.510 & $0.908^{*}$ & $0.901^{*}$ & 0.396 \\
\hline Thickness & & & & & 0.780 & 0.795 & $0.964^{*}$ \\
\hline Volume & & & & & & 0.999* & 0.706 \\
\hline FW & & & & & & & 0.722 \\
\hline
\end{tabular}

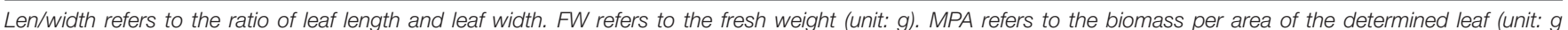

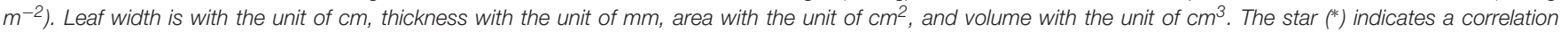
coefficient $>0.9$.

leaf traits showed different divergences in these populations. The physiological traits (such as diel acidity changes, leaf florescence parameters, and etc.) were usually measured in the studies of macrophytes exposed to toxicity or under other stress due to the sensitive responses (Zhang et al., 2014; Shao et al., 2017). While in this study, the physiological traits were less sensitively divergent than morphological ones (seven clusters) among the eight populations, probably reflecting the physiological adaptation to the clear water conditions benign for the growth of Ottelia. The quantitatively determined traits showed to some extent 


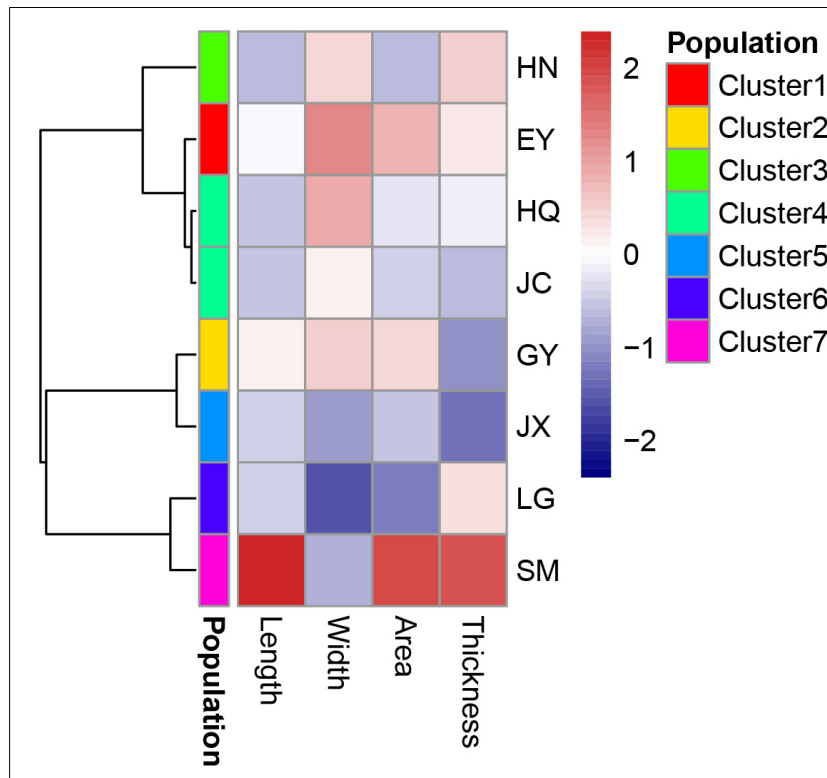

FIGURE 7 | The cluster analysis of leaf traits of morphology and biomass in the eight populations. Leaf length and width is with the unit of $\mathrm{cm}$, area with the unit of $\mathrm{cm}^{2}$ and thickness with the unit of $\mathrm{mm}$.

correlation with the phylogenetic relationship, implying that variation or speciation of Ottelia in these isolated water systems have produces various traits in each population. For example, the morphological traits were clustered into seven groups (the two populations from the same O. acuminata var. acuminata were merged into one cluster), and the $\mathrm{HN}$ population was singled out base on the carbon-related traits. This is consistent with the results of $\mathrm{He}$ (1991) using several qualitative or semi-quantitative traits such as flower, seed and other structures. We also found special features within two populations. The SM population (O. acuminata var. songmingensis) had thickest and longest leaves in all the population and interestingly with calcium precipitation on both sides of the leaves, an interesting phenomenon that requires further study. The $\mathrm{HN}$ population (O. cordata) had high diel acidity changes, only similar with $O$. alismoides but not with other species in the genus Ottelia in China, which provided a clue for future phylogenetic research.

The leaf functional traits have been well investigated in terrestrial plants, and the photosynthesis rate, leaf weight per area and leaf life span of $>2,000$ species of plants have been recorded (Wright et al., 2004). The authors proposed a LES and claimed that there was a typical trade-off between leaf functional traits that leaves with high photosynthesis rate are featured low life span and low leaf MPA (Wright et al., 2004). To our knowledge, this study is the first attempt to systematically analyze the leaf functional traits in submerged freshwater macrophytes. The low leaf MPA and high photosynthesis rate of the Ottelia leaves fit well with LES and placed in the spectrum of the quick return on nutrient and biomass investment. Accordingly, the leaf life span of Ottelia was expected to be short as other submerged species (Hemminga et al., 1999; Yamamoto et al., 1999; Kamermans et al., 2001). In addition, Cornwell et al. (2010) revealed the predominant influence of plant functional traits on decomposition rates at a global scale. Based on our findings on functional traits of Ottelia populations, the decomposition rate and carbon turnover of these populations should be very fast, similar to Potamogeton crispus (Wang et al., 2016), and thus a fast carbon cycling was expected for the Ottelia-dominated karst freshwaters. However, our results, together with Yin et al. (2017), indicated that all the species or varieties of the genus Ottelia in China could use bicarbonate as inorganic carbon supply though there was variation among the populations. Similar like Potamogeton lucens (Prins et al., 1982), the Ottelia leaves were expected with polarity of $\mathrm{pH}$ between the adaxial and abaxial side, but with much broader leaves probably stronger effects on the polarity. Therefore, the calcium precipitation (as $\mathrm{CaCO}_{3}$ ) on the surfaces of Ottelia leaves could bring abundant carbon burial when the macrophytes were dominant producers and thus strongly affect the carbon cycling. Thirdly, high diel acidity changes $>10 \mu$ equiv $\mathrm{g}^{-1} \mathrm{FW}$ were found even at high inorganic carbon supply, which is potentially inducible CAM feature similar with that $O$. alismoides showed in Shao et al. (2017). A dense macrophyte bed with strong CAM capacity could also affect the $\mathrm{pH}$ of water column at night (Keeley, 1983). Consequently, the changes of $\mathrm{pH}$ have a strong effect on the inorganic carbon species in the water column and other primary producers, e.g., periphyton on the leaves (Maberly, 1996; Hao et al., 2017). In summary, the role of Ottelia populations on the carbon cycles in the karst freshwaters warrants further studies.

There is also small variation of plant traits among the three populations (HQ, EY, and JC) belonging to the same variety O. acuminata var. acuminata. The lower end-point $\mathrm{pH}$ in EY population concurred with habitat fragmentation and destruction in Eryuan County. During our field survey, we found that the natural populations of $O$. acuminata var. lunanen and $O$. emersa disappeared due to habitat destruction. The extinct of the Ottelia populations should be highlighted in the future projects of macrophyte conservation.

\section{CONCLUSION}

Our trait analyses profiled the eight populations of genus Ottelia in details. With the unique growth form Otteliids and limited distribution in the localized area, the investigated species or varieties may form special effects on the growing freshwaters distinct from other submerged species. Our results indicated an important ecological role of submerged macrophyte Ottelia spp. in the karst freshwaters. More studies about whether direct uptake of bicarbonate or relying on extracellular carbonic anhydrase in Ottelia leaves would provide more accurate knowledge about the effects of the species on other primary producers and the carbon cycling in the karst freshwaters.

\section{AUTHOR CONTRIBUTIONS}

YC, WL, and HJ designed the experiments. YC and LX determined the physic-chemical variables. YL determined the leave morphology. LN determined the photosynthesis rate. 
HJ determined the acidity of leaves. YC and HJ wrote the first edition of the manuscript, and other co-authors contributed to the modification of the manuscript.

\section{FUNDING}

This research was supported by the Strategic Priority Research Program of Chinese Academy of Sciences, Grant No. XDB31010000 and the National Natural Science Foundation of China (31870345 and 31670368).

\section{REFERENCES}

Cao, Y., Li, W., and Jeppesen, E. (2014). The response of two submerged macrophytes and periphyton to elevated temperatures in the presence and absence of snails: a microcosm approach. Hydrobiologia 738, 49-59. doi: 10. 1007/s10750-014-1914-5

Cao, Y., Olsen, S., Gutierrez, M. F., Brucet, S., Davidson, T. A., Li, W., et al. (2017). Temperature effects on periphyton, epiphyton and epipelon under a nitrogen pulse in low-nutrient experimental freshwater lakes. Hydrobiologia 795, 267-279. doi: 10.1007/s10750-017-3140-4

Chen, J.-M., Du, Z.-Y., Long, Z.-C., Gichira, A. W., and Wang, Q.-F. (2017). Molecular divergence among varieties of Ottelia acuminata (Hydrocharitaceae) in the yunnan-guizhou plateau. Aquat. Bot. 140, 62-68. doi: 10.1016/j.aquabot. 2017.03.001

Chen, Y.-Y., Li, X.-L., Yin, L.-Y., and Li, W. (2008). Genetic diversity of the threatened aquatic plant Ottelia alismoides in the yangtze river. Aquat. Bot. 88, 10-16. doi: 10.1016/j.aquabot.2007.08.002

Clement, R., Dimnet, L., Maberly, S. C., and Gontero, B. (2016). The nature of the $\mathrm{CO} 2$-concentrating mechanisms in a marine diatom, Thalassiosira pseudonana. New Phytol. 209, 1417-1427. doi: 10.1111/nph.13728

Cook, C. D. K., Symoens, J.-J., and Urmi-König, K. (1984). A revision of the genus Ottelia (hydrocharicaea) I. generic considerations. Aquat. Bot. 18, 263-274. doi: 10.1016/0304-3770(84)90068-8

Cornwell, W. K., Cornelissen, J. H., Amatangelo, K., Dorrepaal, E., Eviner, V. T., Godoy, O., et al. (2010). Plant species traits are the predominant control on litter decomposition rates within biomes worldwide. Ecol. Lett. 11, 1065-1071. doi: 10.1111/j.1461-0248.2008.01219.x

Damián, X., Fornoni, J., Domínguez, C. A., and Boege, K. (2018). Ontogenetic changes in the phenotypic integration and modularity of leaf functional traits. Funct. Ecol. 32, 234-246. doi: 10.1111/1365-2435.12971

Epstein, D. M., Wurtsbaugh, W. A., and Baker, M. A. (2012). Nitrogen partitioning and transport through a subalpine lake measured with an isotope tracer. Limnol. Oceanogr. 57, 1503-1516. doi: 10.4319/lo.2012.57.5.1503

Fu, H., Yuan, G., Lou, Q., Taotao, D., Xu, J., Cao, T., et al. (2018). Functional traits mediated cascading effects of water depth and light availability on temporal stability of a macrophyte species. Ecol. Indic. 89, 168-174. doi: 10.1016/j.ecolind. 2018.02.010

Fu, H., Zhong, J., Yuan, G., Xie, P., Guo, L., Zhang, X., et al. (2014). Trait-based community assembly of aquatic macrophytes along a water depth gradient in a freshwater lake. Freshw. Biol. 59, 2464-2471. doi: 10.1111/fwb.12443

Grime, J. P. (1974). Vegetation classification by reference to strategies. Nature 250, 26-31. doi: $10.1038 / 250026 \mathrm{a} 0$

Hao, B., Wu, H., Cao, Y., Xing, W., Jeppesen, E., and Li, W. (2017). Comparison of periphyton communities on natural and artificial macrophytes with contrasting morphological structures. Freshw. Biol. 62, 1783-1793. doi: 10.1111/fwb.12991

He, J. B. (1991). Systematic Botanical and Biosystematic Studies on Ottelia in China. Wuhan: Wuhan University Press.

Hemminga, M. A., Marba, N., and Stapel, J. (1999). Leaf nutrient resorption, leaf lifespan and the retention of nutrients in seagrass systems. Aquat. Bot. 65, 141-158. doi: 10.1016/S0304-3770(99)00037-6

Huang, X. F., Chen, W. M., and Cai, Q. M. (1999). "Survey, observation and analysis of lake ecology," in Standard Methods for Observation and Analysis

\section{ACKNOWLEDGMENTS}

We are grateful to Zhizhong Li, Yu Cheng, Ying Zhang, Haisu Wang, and Quan Jin during the field sampling.

\section{SUPPLEMENTARY MATERIAL}

The Supplementary Material for this article can be found online at: https://www.frontiersin.org/articles/10.3389/fpls.2018.01938/ full\#supplementary-material

in Chinese Ecosystem Research Network, Series V, (Beijing: Standards Press of China).

Jeppesen, E., Sondergaard, M., Sondergaard, M., and Christofferson, K. (1998). The Structuring Role of Submerged Macrophytes in Lakes. New York, NY: Springer Science \& Business Media. doi: 10.1007/978-1-46120695-8

Jespersen, A.-M., and Christoffersen, K. (1987). Measurements of chlorophyll-a from phytoplankton using ethanol as extraction solvent. Arch. Hydrobiol. 109, 445-454. doi: 10.3791/51441

Jiang, H. S., Yin, L. Y., Ren, N. N., Zhao, S. T., Li, Z., Zhi, Y., et al. (2017). Silver nanoparticles induced reactive oxygen species via photosynthetic energy transport imbalance in an aquatic plant. Nanotoxicology 11, 157-167. doi: 10. 1080/17435390.2017.1278802

Kamermans, P., Hemminga, M. A., Marbà, N., Mateo, M. A., Mtolera, M., and Stapel, J. (2001). Leaf production, shoot demography, and flowering of Thalassodendron ciliatum along the east African coast. Aquat. Bot. 70, 243-258. doi: 10.1016/S0304-3770(01)00156-5

Kaul, R. B. (1969). Morphology and development of the flowers of Boottia cordata, Ottelia alismoides, and their synthetic hybrid (Hydrocharitaceae). Am. J. Bot. 56, 951-959. doi: 10.1002/j.1537-2197.1969.tb09746.x

Keeley, J. E. (1983). Crassulacean acid metabolism in the seasonally submerged aquatic Isoetes howellii. Oecologia 58, 57-62. doi: 10.1007/BF0038 4542

Kirk, J. T. O. (1977). Attenuation of light in natural waters. Mar. Freshw. Res. 28, 497-508. doi: 10.1071/MF9770497

Klimešová, J., Tackenberg, O., and Herben, T. (2016). Herbs are different: clonal and bud bank traits can matter more than leaf-height-seed traits. New Phytol. 210, 13-17. doi: 10.1111/nph.13788

Kraft, N. J. B., Godoy, O., and Levine, J. M. (2015). Plant functional traits and the multidimensional nature of species coexistence. Proc. Natl. Acad. Sci. U.S.A. 112, 797-802. doi: 10.1073/pnas.1413650112

Kraft, N. J. B., Valencia, R., and Ackerly, D. D. (2008). Functional traits and nichebased tree community assembly in an amazonian forest. Science 322, 580-582. doi: 10.1126/science.1160662

Kramer, D. M., Johnson, G., Kiirats, O., and Edwards, G. E. (2004). New fluorescence parameters for the determination of QA redox state and excitation energy fluxes. Photosynth. Res. 79, 209-218. doi: 10.1023/B:PRES.0000015391. 99477.0d

Li, Z.-Z., Lu, M.-X., Gichira, A. W., Islam, M. R., Wang, Q.-F., and Chen, J.-M. (2018). Genetic diversity and population structure of Ottelia acuminata var. jingxiensis, an endangered endemic aquatic plant from southwest China. Aquat. Bot. 152, 20-26. doi: 10.1016/j.aquabot.2018.09.004

Liu, X., and Wang, H. (2018). Contrasting patterns and drivers in taxonomic versus functional diversity, and community assembly of aquatic plants in subtropical lakes. Biodivers. Conserv. 27, 3103-3118. doi: 10.1007/s10531-0181590-2

Maberly, S. C. (1996). Diel, episodic and seasonal changes in $\mathrm{pH}$ and concentrations of inorganic carbon in a productive lake. Freshw. Biol. 35, 579-598. doi: 10.1111/j.1365-2427.1996.tb01770.x

Maberly, S. C., and Gontero, B. (2017). Ecological imperatives for aquatic carbon dioxide-concentrating mechanisms. J. Exp. Bot. 68, 3797-3814. doi: 10.1093/ jxb/erx201 
Olsen, S., Cao, Y., Florencia Gutierrez, M., Brucet, S., Landkildehus, F., Lauridsen, T. L., et al. (2017). Effect of a nitrogen pulse on ecosystem $\mathrm{N}$ processing at different temperatures: a mesocosm experiment with 15NO3-addition. Freshw. Biol. 62, 1232-1243. doi: 10.1111/fwb.12940

Petter, G., Wagner, K., Wanek, W., Sánchez Delgado, E. J., Zotz, G., Cabral, J. S., et al. (2016). Functional leaf traits of vascular epiphytes: vertical trends within the forest, intra- and interspecific trait variability, and taxonomic signals. Funct. Ecol. 30, 188-198. doi: 10.1111/1365-2435.12490

Prins, H. B. A., Snel, J. F. H., Zanstra, P. E., and Helder, R. J. (1982). The mechanism of bicarbonate assimilation by the polar leaves of potamogeton and elodea-CO2 concentrations at the leaf surface. Plant Cell Environ. 5, 207-214. doi: 10.1111/1365-3040.ep11571916

Shao, H., Gontero, B., Maberly, S. C., Jiang, H. S., Cao, Y., Li, W., et al. (2017). Responses of Ottelia alismoides, an aquatic plant with three CCMs, to variable CO2 and light. J. Exp. Bot. 68, 3985-3995. doi: 10.1093/jxb/erx064

Wang, H. J., Wang, H. Z., Liang, X. M., Pan, B. Z., and Kosten, S. (2016). Macrophyte species strongly affects changes in C, N, and P stocks in shallow lakes after a regime shift from macrophyte to phytoplankton dominance. Inl. Waters 6, 449-460. doi: 10.1080/IW-6.3.837

Wang, P., Hu, G., and Cao, J. (2017). Stable carbon isotopic composition of submerged plants living in karst water and its eco-environmental importance. Aquat. Bot. 140, 78-83. doi: 10.1016/j.aquabot.2017.03.002

Wetzel, R. G. (1964). A comparative study of the primary production of higher aquatic plants, periphyton, and phytoplankton in a large, shallow lake. Int. Rev. Hydrobiol. 49, 1-61. doi: 10.1002/iroh.19640490102

Wright, I. J., Reich, P. B., Mark, W., Ackerly, D. D., Zdravko, B., Frans, B., et al. (2004). The worldwide leaf economics spectrum. Nature 428, 821-827. doi: $10.1038 /$ nature 02403
Yamamoto, I., Tsuchiya, T., and Ikusima, I. (1999). Relationship between net photosynthetic rate and leaf life span of six submerged plants in experimental ponds. Jpn. J. Limnol. 60, 257-263. doi: 10.3739/rikusui.60.257

Yin, L., Li, W., Madsen, T. V., Maberly, S. C., and Bowes, G. (2017). Photosynthetic inorganic carbon acquisition in 30 freshwater macrophytes. Aquat. Bot. 140, 48-54. doi: 10.1016/j.aquabot.2016.05.002

Yin, L., Wang, C., Chen, Y., Cao, Y., Cheng, Y., and Li, W. (2009). Cold stratification, light and high seed density enhance the germination of Ottelia alismoides. Aquat. Bot. 90, 85-88. doi: 10.1016/j.aquabot.2008.05.002

Yin, L., Zhang, R., Xie, Z., Wang, C., and Li, W. (2013). The effect of temperature, substrate, light, oxygen availability and burial depth on Ottelia alismoides seed germination. Aquat. Bot. 111, 50-53. doi: 10.1016/j.aquabot.2013.09.001

Zhang, Y., Yin, L., Jiang, H. S., Li, W., Gontero, B., and Maberly, S. C. (2014). Biochemical and biophysical CO2 concentrating mechanisms in two species of freshwater macrophyte within the genus Ottelia (Hydrocharitaceae). Photosynth. Res. 121, 285-297. doi: 10.1007/s11120-013-9950-y

Conflict of Interest Statement: The authors declare that the research was conducted in the absence of any commercial or financial relationships that could be construed as a potential conflict of interest.

Copyright (C) 2019 Cao, Liu, Ndirangu, Li, Xian and Jiang. This is an open-access article distributed under the terms of the Creative Commons Attribution License (CC BY). The use, distribution or reproduction in other forums is permitted, provided the original author(s) and the copyright owner(s) are credited and that the original publication in this journal is cited, in accordance with accepted academic practice. No use, distribution or reproduction is permitted which does not comply with these terms. 